\title{
Resenha
}

\section{Resenha Queixa Escolar}

\author{
Review School Complaints
}

\author{
Reseña Queja Escolar
}

\author{
Lúcia Veiga Schermack \\ Universidade Federal de São Carlos - SP
}

Nilza S.T. Leonado; Zaira F.R.G Leal; Solange P.M. Rossato. (Org.). Pesquisas em Queixa Escolar. Desvelando e desmistificando o cotidiano escolar. $1^{\text {a }}$ ed. Maringá: EDUEM, 2012.

O livro Pesquisas em queixa escolar: desvelando e desmistificando o cotidiano escolar reúne estudos que tratam a queixa escolar à luz da perspectiva teórica da Psicologia Histórico-Cultural. A perspectiva adotada expõe os determinantes sociais, históricos, econômicos e culturais para a compreensão e apreensão de um fenômeno - neste caso, a queixa escolar e as dificuldades de aprendizagem, as quais estão presentes em muitas crianças no cotidiano das escolas.

De acordo com as autoras, a temática não é nova, pois as pesquisas relacionadas ao fracasso escolar remontam a algumas décadas. O que difere e dá importância a esta obra é a perspectiva na qual são apresentadas as análises e propostas de intervenções. Nos estudos apresentados percebe-se a tentativa de considerar os múltiplos determinantes que podem influenciar e causar as dificuldades de aprendizagem. Esta perspectiva rompe e critica uma visão unilateral, fragmentada ou reducionista do problema, que culpa ora o aluno, ora a família, ora as instituições ou outras instâncias pelo não aprender. A adoção desta perspectiva mais ampla e totalizadora tem por finalidade desvelar e desmistificar uma visão hegemônica e padronizada dos estudos realizados na área da queixa escolar.

No primeiro capítulo é apresentado pelas autoras organizadoras da obra o Estado da Arte sobre queixa escolar no período de 1990 a 2009, a partir de uma pesquisa rea- lizada nos principais indexadores nacionais. O objetivo do estudo foi caracterizar as concepções, tendências e abordagens teórico-metodológicas adotadas nas pesquisas sobre a queixa escolar neste período.

Após fazer uma análise histórica da situação do fracasso escolar com base em dados estatísticos do IBGE/ INEP, as pesquisadoras mostram que no Brasil os problemas da escolarização remontam ao século passado, e afirmam que a escola não tem conseguido desempenhar sua função de proporcionar aos seus alunos a apropriação do conhecimento histórico, social e humano. Avaliam que, embora na última década forças políticas e projetos tenham propiciado a entrada e a permanência de quase todas as crianças na escola $(97,3 \%)$, não é garantida a elas o direito de aprendizagem e desenvolvimento mínimo esperado. Este dado aponta que, num passado remoto, o desafio maior da educação brasileira era viabilizar mecanismos para que todas as crianças estivessem na escola e diminuir os altos índices de repetência e evasão escolar. Atualmente, pode-se dizer que há outro grande desafio: proporcionar qualidade de ensino e aprendizagem efetiva às crianças que estão na escola.

Diante do cenário de precariedade do ensino público, em que muitas crianças estão marginalizadas do direito de aprender no seu sentido mais amplo, constata-se um crescimento das queixas escolares e, consequentemente, de encaminhamentos a especialistas de diversas áreas. Tais 
queixas representam, de fato, um conjunto de obstáculos e dificuldades de professores e alunos em relação ao ensino-aprendizagem no cotidiano escolar.

Ao longo dos tempos, muitas foram as explicações e justificativas dadas para as queixas de dificuldades de aprendizagem dos alunos. No entanto, ao analisar inúmeros trabaIhos e pesquisas, as autoras perceberam que grande parte desses estudos centra-se na figura do aluno que não aprende, seja por questões biológicas, seja por aspectos institucionais (como a família), seja ainda pela má formação profissional do professor. Apenas uma pequena proporção destes estudos busca explicar a queixa escolar como produto das relações sociais, políticas públicas e produção histórico-social.

Devido a esta análise simplista e individualizada, emerge uma patologização no ensino na tentativa de explicar o não aprender por inúmeros rótulos para enumerar e enquadrar as dificuldades de aprendizagem, sem considerar outros aspectos que interferem e contribuem para essas dificuldades.

Ao fazer um balanço dos 77 artigos lidos e analisados, as autoras perceberam uma grande tendência em tentar compreender a queixa escolar por uma única ótica, de forma particular e compartimentalizada. Adotar um aspecto específico não possibilita identificar a real causa do problema, tampouco proporciona uma intervenção eficaz; ao contrário, pode acabar atribuindo ao problema uma causa distorcida e errônea. É necessário relacionar todos os aspectos envolvidos no fenômeno da dificuldade de aprendizagem (individual, social, histórico, político, econômico, institucional) compreendendo as contradições e limitações existentes.

No segundo capítulo as autoras (Valéria Garcia da Silva e Nilza Sanches Tessaro Leonardo) apresentam uma pesquisa sobre as percepções dos professores de uma escola pública sobre como se dá o desenvolvimento psíquico. Neste contexto, discorrem sobre como se processa o desenvolvimento psíquico infantil na perspectiva da teoria da Psicologia Histórico-Cultural na segunda infância (sete a dez anos), analisando as implicações deste desenvolvimento no processo de aprendizagem e na queixa escolar.

É interessante a forma como alguns conceitos da teoria vigotskiana são trabalhados pelas autoras no intuito de demonstrar como a linguagem e as relações sociais ao longo da história humana possibilitaram a apropriação e o desenvolvimento do psiquismo e ainda impulsionam um aprimoramento da espécie humana que não se extingue. O conhecimento científico, que é elaborado e instituído ao longo do tempo, deve ser apropriado e trabalhado na escola, já que esta é um espaço para promoção do desenvolvimento das funções elementares superiores (memória, abstração, lógica, atenção e outras). No estudo é possível compreender, com muita clareza, que as funções psicológicas elementares aprimoram-se e constituem-se progressivamente em funções superiores e que o professor pode auxiliar na mediação deste processo ao priorizar os conhecimentos científicos, colocando em posição secundária os conhecimentos espontâneos do cotidiano dos alunos.

$\mathrm{Na}$ pesquisa realizada, a maioria dos professores relata considerar mais importante trabalhar com conteúdos da realidade do aluno, o que é uma questão preocupante, já que este tipo de conhecimento não possibilita a utilização de mecanismos psicológicos mais complexos e capazes de propiciar o desenvolvimento das funções superiores. Este esvaziamento e desprestígio dos saberes científicos na escola promove uma aprendizagem superficial que, segundo as autoras, é decorrente da valorização dos saberes populares em detrimento dos conhecimentos científicos, o que pode justificar muitas das dificuldades de aprendizagem e a origem de tantas queixas escolares.

No terceiro capítulo, Cristiane Toller Bray faz o relato de uma pesquisa realizada com o objetivo de perceber as diferenças das percepções dos professores sobre a queixa escolar em escolas públicas e privadas. O estudo demonstrou que as queixas aparecem em ambas as instituições, predominando a tendência dos professores a individualizar a causa dos problemas de aprendizagem. Outro dado apontado na pesquisa é o de que, nas escolas particulares, veicula-se a crença de que, por uma questão econômica, o número de pais que buscam uma assistência extraescolar com especialistas para as "possíveis" dificuldades dos filhos é muito maior.

Indo na contramão do discurso hegemônico de que os problemas da escola pública são muito diferentes e maiores do que os da escola particular, a pesquisa mostrou que problemas existem nas duas categorias institucionais, conjecturando que muitos dos dilemas e contradições em torno das concepções e tratativas em relação às dificuldades de aprendizagem estão subjacentes a uma problemática mais ampla, que é a social. Tudo isto contribui para desmistificar a crença de que o fracasso escolar é um fenômeno típico da escola pública.

O quarto capítulo traz o relato de uma pesquisa realizada por Solange Rossato e Nilza Leonardo em algumas escolas especiais, com o intuito de verificar como as queixas escolares são consubstanciadas e compreendidas pelos professores da Educação Especial e em que sentido elas se diferenciam daquelas produzidas no ensino regular. O trabalho faz uma breve contextualização histórica do Ensino Especial, apresentando algumas concepções e justificativas para explicar as deficiências ao longo dos tempos. As autoras discutem alguns princípios epistemológicos da teoria vigosktyana e analisam os dados da pesquisa, a qual identificou a dificuldade que grande parte dos professores tem em compreender e identificar as queixas escolares no cotidiano das escolas especiais, seja pela baixa expectativa de aprendizagem, seja pelo fato de este grupo de alunos não estar inserido no perfil de aluno ideal. Os estigmas e estereótipos, atrelados à crença relativa à incapacidade dos deficientes, veem na figura e no corpo destes alunos as causas de não aprenderem e, consequentemente, atribuem a eles mesmos a culpa pelo fracasso escolar. Desmembram o aspecto individual do social e intraescolar para explicar e justificar os fenômenos educacionais.

$\mathrm{Na}$ perspectiva neoliberal, em que se busca a eficiência e qualidade por intermédio de avaliações em larga escala, os alunos da Educação Especial acabam não se enquadrando nesta lógica que tende a homogeneizar as 
metas, expectativas e ritmos de aprendizagem. É nesta perspectiva que se explicam alguns achados da pesquisa, a qual identificou a forma como os pesquisadores entrevistados entendem e diferenciam a dificuldade de aprendizagem de alunos com deficiência intelectual e suas relações com a queixa escolar. Um grande número de professores entende que a dificuldade de aprendizagem é transitória, focal e possível de ser sanada. Já a deficiência intelectual é definitiva e generalizada, não podendo ser superada. Esta concepção implica em uma prática educativa que considera a deficiência um comprometimento orgânico que é irreversível e compromete o processo de aprendizagem, sendo, por isto, inviabilizada a possibilidade de tais crianças vivenciarem o processo de compensação e autocompensação. Ora, se a deficiência é um atributo cristalizado do sujeito, o que os professores podem fazer e esperar dos seus alunos?

Nota-se que as dificuldades apresentadas na Educação Especial tendem a ser naturalizadas e entendidas como algo normal à condição biológica do portador da deficiência. Tal crença traz implicações para a prática e o ofício do educador, o qual, com esta concepção de impossibilidade, não propiciará a seus alunos oportunidades ricas de trocas e construções de conhecimento.

No capítulo seguinte, Roberta Reis e Maria Júlia Ribeiro relatam a experiência adquirida em um projeto de extensão no Laboratório Temático de Inclusão e Diversidade da Universidade Estadual de Maringá. O objetivo do projeto era apoiar pedagogicamente alunos de escolas públicas com problemas na escolarização. Foi identificado, a partir dos formulários de ingresso, que as maiores demandas eram de dificuldades de aprendizagem $(53,9 \%)$ e de Transtorno de Déficit de Atenção e Hiperatividade- TDHA (19,4\%).

Para explicar e compreender as causas que subjazem à quantidade e tipologia das queixas, as autoras analisam, com base na literatura cientifica específica, como os principais autores da área explicam a forma como as dificuldades de aprendizagem têm sido engendradas no cotidiano escolar e as implicações do crescimento de diagnósticos de TDHA. As contribuições de Patto (1985), Moysés e Collares (1996) apontam algumas crenças criadas em torno do fracasso escolar que são constituídas e cristalizadas como mitos para explicar o não aprender: mito da carência cultural, mito da carência afetiva, mito da ineficácia da escola pública, mito da desnutrição e outros - que, numa perspectiva unívoca de análise, incluem ou excluem um elemento esquecendo outro que também deveria ser elencado na análise.

Também são apresentados argumentos que comprovam serem estes mitos infundados e insustentáveis, uma vez que compreendem a dificuldade de aprendizagem como mera questão de ordem biologizante, estabelecendo assim frágil dependência entre educação e saúde. Disso deriva outro fenômeno educacional crescente e preocupante, que é a patologização e medicalização dos problemas educacionais. Por mínimos problemas comportamentais ou pedagógicos da escolarização, alunos têm sido encaminhados para postos de saúde ou clínicas especializas, sem qualquer questionamento sobre a real função da escola. Laudos pedidos pela escola aos pais para justificar a não aprendizagem fazem com que a instituição seja isentada de culpa pela problemática, pois, em seu entendimento, é algo que não cabe a ela resolver, e assim ela transfere a intervenção a outro órgão ou a alguém que ela entenda ser especialista naquela questão específica.

Finalizando o livro, Marilena Proença e Zaira Leal apresentam "A queixa escolar sob a perspectiva do aluno", com base numa pesquisa realizada com grupos de alunos do $3^{\circ}$ ano do Ensino Médio. Neste trabalho, algo que merece destaque é que o aluno não é tido apenas como alvo das queixas dos professores e pais, mas ele próprio também protagoniza o papel de expressar queixas em relação a diversas questões do cotidiano escolar. Dando voz à fala dos alunos para tentar entender o quadro das constantes lamentações e queixas em que se tornou o palco escolar, foi possível perceber a dificuldade de esses alunos compreenderem o real sentido da escola, uma vez que a veem como um espaço para encontrar os amigos e divertir-se, considerando-a um local chato e repetitivo. Eles sentiram dificuldade inclusive em manifestar qual contribuição a escola trazia para suas vidas, o que evidencia o esvaziamento de significado e importância da escola como espaço para humanização, construção e apropriação dos conhecimentos historicamente construídos.

No cenário educacional, os professores encontram-se insatisfeitos e expõem inúmeras queixas em relação aos alunos e ao sistema precário, e relação às famílias, que não se envolvem nem os apoiam. Os alunos, por sua vez, em sua maioria, queixam-se do despreparo, das metodologias e práticas enfadonhas dos professores. Este embate, na verdade, é um retrato de uma escola permeada por contradições e conflitos, revelando que a principal queixa é, na verdade, relativa ao sistema de ensino e seu estado caótico. Por trás deste descompasso e insatisfação generalizada dos vários protagonistas da escola percebe-se que não cabe mais culpar uma instância específica, mas alertar para a necessidade de buscar soluções e alternativas que contribuam para a mudança deste quadro.

A obra configura-se como leitura imprescindível para aqueles que queiram compreender e ampliar a problemática das queixas escolares, estudadas sob o prisma teórico metodológico da Psicologia Histórico Cultural. 


\section{Sobre a autora}

Lúcia Veiga Schermack (lucveiga@hotmail.com)

Mestranda em Educação na Universidade Federal de São Carlos. Formada em Letras pela Universidade Federal de Ouro Preto. 